\title{
Granulated organic and mineral fertilizers: Technology and utility properties
}

\author{
${ }^{1,}$ Czesława Rosik-Dulewska, ${ }^{2}$ Jolanta Robak, ${ }^{1}$ Katarzyna Głowala \\ ${ }^{1}$ Institute of Environmental Engineering of the Polish Academy of Science (IPIŚ PAN), 41-819 Zabrze, ul. M.Skłodowskiej- \\ Curie 34, Poland, e-mail: dulewska@ipis.zabrze.pl, glowala@ipis.zabrze.pl \\ ${ }^{2}$ Institute for Chemical Processing of Coal (IChPW), 41-803 Zabrze, ul. Zamkowa 1, e-mail: jrobak@ichpw.zabrze.pl \\ (corresponding author) \\ ${ }^{3}$ University of Opole, Chair of Protection of Earth's Surface, 45-952 Opole, Oleska 22, e-mail: kopz@uni.opole.pl
}

\begin{abstract}
This work presents the selected aspects of a technological concept for the production of organic and mineral fertilizers from communal sludge stabilized with volatile ash, by using two methods of granulation: coating and pressure. The presented concept is the effect of optimization, taking into account an interference of a number of factors exerted onto the fertilizing values and the mechanical strength of the final products. The fertilizers (contain ash from brown coal) obtained according to that method are characterized by a sufficient (according to law) content of organic matter $(35,73 \% \mathrm{w} / \mathrm{w})$, total nitrogen $(1,70 \% \mathrm{w} / \mathrm{w})$, phosphorus $\mathrm{P}_{2} \mathrm{O}_{5}$ $(3,62 \% \mathrm{w} / \mathrm{w})$ and after the modification, also potassium $\mathrm{K}_{2} \mathrm{O}(8,43 \% \mathrm{w} / \mathrm{w})$. The mechanical properties are better for the granulates, prepared by using pressure granulation $\left(15,1 \mathrm{kG} / \mathrm{cm}^{2}\right)$ and allow for their transportation, storage and application.
\end{abstract}

Keywords: organic and mineral fertilizers, sludge, volatile ashes, granulation.

Presented at VII Conference Wasteless Technologies and Waste Management in Chemical Industry and Agriculture, Międzyzdroje, 12 - 15 June, 2007.

\section{INTRODUCTION}

The superior legal act governing the waste management in Poland is the Act on Waste of 27 April 2001, according to which the basic directions of waste disposal include as follows: i) prevention or reduction of waste quantity and their noxiousness to the environment, ii) material recovery from waste by their re-use, iii) waste neutralization.

Both the sludge from communal wastewater treatment plants and the volatile ashes generated in the professional energetics are waste materials that are unavoidable. Their permanent availability, great quantities and properties cause that works on their further utilization have been in progress from many years. However, the condition for sludge and volatile ashes management is to give them proper utility values, inclusive of the physical form. The areas of economic utilization of the aforementioned waste include among other things agriculture and land reclamation $^{1,2}$.

The example of technology binding utilization of both wastes is the method of the granulated organic and mineral fertilizer production presented in this work. The objective of the conducted research was to work out the technology of the production of the mechanically stabile organic and mineral product of fertilizing properties basing on sludge and volatile ashes. The technology allows for the utilization of the fertilizing values of sludge on the one hand, including the organic substance susceptible to mineralization and macroelements ${ }^{3}$, and the binding and hygienizing properties of volatile ashes, on the other hand ${ }^{4}$.

\section{TECHNOLOGICAL ASSUMPTIONS}

The properties and the proportion of raw materials are decisive for the fertilizing properties of the new product. The same, physical parameters, such as the grain size, the bulk density and the mechanical strength are conditional on mutual proportions of the components and the method of their initial preparation, the applied forming technology and the final treatment of the product ${ }^{5,6}$.

While designing the technology concept the following assumptions were made:

- communal sludge deposit must meet the requirements of the ordinance of the Minister of Environment on communal sludge ${ }^{7}$,

- the final product should be characterized by the contents of fertilizing constituents consistent with the ordinance of the Minister of Agriculture and Village Development on the execution of some regulations of the act on fertilizers and fertilizing ${ }^{8}$ as well as with the physical values (the grain size and the mechanical strength) allowing for their storage, transport and application at a place of destination.

Two optimization targets, showing mutual discrepancy are the effect of the assumptions:

- maximization of the share of sludge decisive for the fertilizing properties of the fertilizer,

- maximization of the share of ash performing the role of the binder decisive for the mechanical properties of the product.

\section{METHODS OF TESTS AND THE CHARACTERISTIS OF RAW MATERIALS}

The raw materials used for the tests were communal sludge deposit, volatile ash from brown and hard coal. The raw materials were subjected to analysis, including the contents of the organic matter, according the PN-75/ $\mathrm{C}-04646.1^{9}$ standard and the vegetable nutrient constituents: total nitrogen according to the PN-75/C $-04576.17^{10}$ standard, phosphorus according to the PN-75/C - 0453711 standard and potassium with the use of the ASA method, after a previous mineralization of the sample in aqua regia. The chemical composition of the ashes, including the contents of phosphorus $\left(\mathrm{P}_{2} \mathrm{O}_{5}\right)$ and potassium $\left(\mathrm{K}_{2} \mathrm{O}\right)$, were determined according to the own procedure „Deter- 
mination of chemical composition of ash according to the X-ray fluorescence method" of the accredited IChPW's Carbochemistry Laboratory and the PN-G-0452810:1998 ${ }^{\mathbf{1 2}}$ standard. Table 1 presents the results of the determination of the contents of macroelements in the used raw materials.

Table 1. The properties of the raw materials applied in technological tests

\begin{tabular}{|l|c|c|c|}
\hline \multirow{2}{*}{$\begin{array}{l}\text { Contents } \\
{[\% \text { w/w dry mass] }}\end{array}$} & Sludge & \multicolumn{2}{|c|}{ Volatile ash } \\
\cline { 3 - 4 } & $\begin{array}{c}\text { From brown } \\
\text { coal }\end{array}$ & $\begin{array}{c}\text { From hard } \\
\text { coal }\end{array}$ \\
\hline $\begin{array}{l}\text { Organic } \\
\text { substance }\end{array}$ & 58,13 & Not determined & $\begin{array}{c}\text { Not } \\
\text { determined }\end{array}$ \\
\hline Total nitrogen & 3,6 & lack & lack \\
\hline $\begin{array}{l}\text { Phosphorus } \\
\left(\mathrm{P}_{2} \mathrm{O}_{5}\right)\end{array}$ & 2,9 & 0,26 & 0,67 \\
\hline Potassium $\left(\mathrm{K}_{2} \mathrm{O}\right)$ & 0,21 & 0,21 & 3,06 \\
\hline
\end{tabular}

Sewage sludge was rich in fertilizing constituents, except for potassium. Fly ash contained phosphorus and potassium only but the ash from hard coal contained more of its elements than the ash of brown coal and more potassium than sewage sludge.

Two methods of granulation were employed in the technological tests: granulation by coating and pressure granulation. Granulation by coating was carried out by using the disc granulator (Eirich firm) with a 1m disc diameter and with adjustable rotation speed. Pressure granulation was carried out by using the ring type mould granulator (PD-1 type, TESTMER Warszawa production) of the nominal capacity from 0,4 to $1,2 \mathrm{Mg} / \mathrm{h}$. There is concentration system with a perforated matrix of $8 \mathrm{~mm}$ diameter and the concentration rolls in the granulator chamber. Granulation was performed at ambient temperature.

The impact strength of the granulates (Shatter test) was carried out according to the customized standard PN-84/ C-87012.05 (determination of mass of granules, which were not crushed below $1 \mathrm{~mm}$ grain after hitting against a steel plate), and the compressive strength according to own procedure consisting in the measurement of the force, which causes a reduction of the granulate layer by $20 \mathrm{~mm}$.

\section{TECHNOLOGICAL TESTS AND DISCUSSION}

Assuming the additive nature of the constituents, the content of the aforementioned basic fertilizing constituents (Table 1) was calculated for various variants. According to the proportions on the disk granulator assumed in calculations, the lots of granulate were created which were subjected to the impact and compressive strengths tests. The results of the calculations were presented in Figure 1 , in comparison with the requirements contained in the suitable ordinance ${ }^{8}$.

Obtaining the quantities of organic substance, nitrogen and phosphorus on the demanded level is assured by the share of sludge dry matter in the granulate above $50 \% \mathrm{w} / \mathrm{w}$. The calculated content of potassium in the granulates with ash from brown coal does not meet the requirements of the ordinance on fertilizers and fertilizing that results from the low contents of that element in raw materials. Due to greater contents of potassium in the ash from hard coal, its calculated contents in the product with that ash meets the requirements.

The granulates obtained, according to the coating method, were characterized by very poor mechanical strength. Hardly 1 to $2 \%$ w/w of granules did not subject to crushing under impact. Due to this fact it was impossible to determine their compressive strength - the level of granulate was reduced by $20 \mathrm{~mm}$ just at the minimal load of the applied hydraulic pressure, corresponding to the force equal to $0,5 \mathrm{kG} / \mathrm{cm}^{2}$.

The method for increasing the mechanical strength of sludge-ash granulates at the assumption of applying not more than $50 \% \mathrm{w} / \mathrm{w}$ share of ash, may consist in changing the mixture moisture or change of technique and the granulating device.

An important parameter of the granulation process is water content in raw materials. It is decisive for the

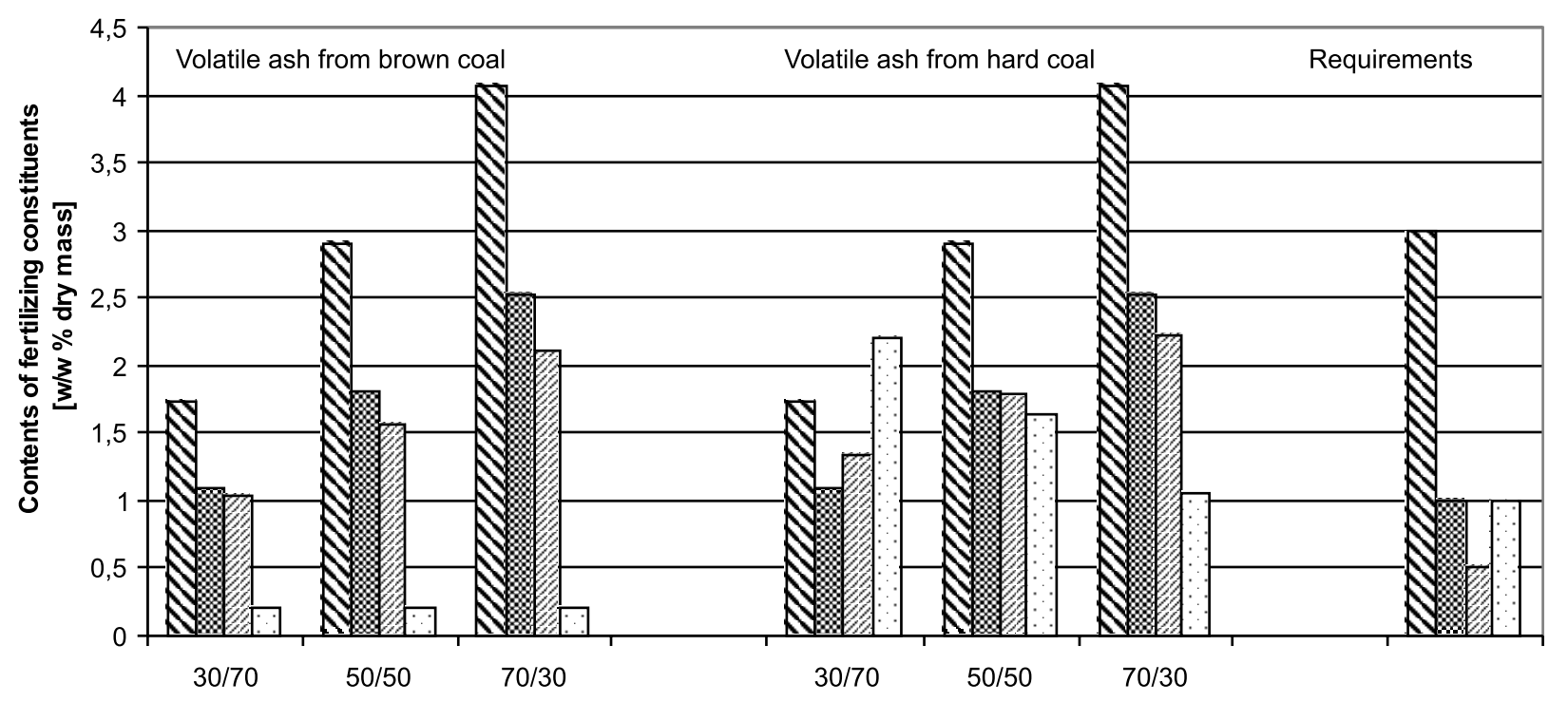

Parts by weight of sludge / ash [weight of dry mass]

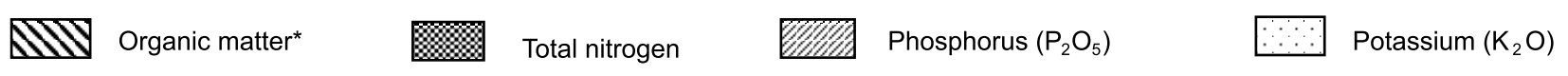

Figure 1. The calculated contents of macroelements in the granulates depending on the origin and the proportion of raw materials $*^{*}$ - the results for the organic matter have been divided by 10 ) 
mechanical strength of the products in which inter-molecular binding is due to the forces present on the border of the phases (liquid bridges, capillary forces and surface tension), as well as permanent bridges, generated as a result of sintering, melting, crystallization and chemical reactions ${ }^{13,14}$, including the chemical reactions taking place during mineral binders hardening, as in the case of volatile ashes application as mechanical stabilizers.

The raw material in the previously produced granulates was the sludge dried to the water contents of $53 \% \mathrm{w} / \mathrm{w}$. In the second series of the tests, the sludge of $76 \% \mathrm{w} / \mathrm{w}$ water contents was utilized. Figure 2 presents the mechanical strength of the obtained granulates depending on the water contents, share and the origin of ash in the mixtures.

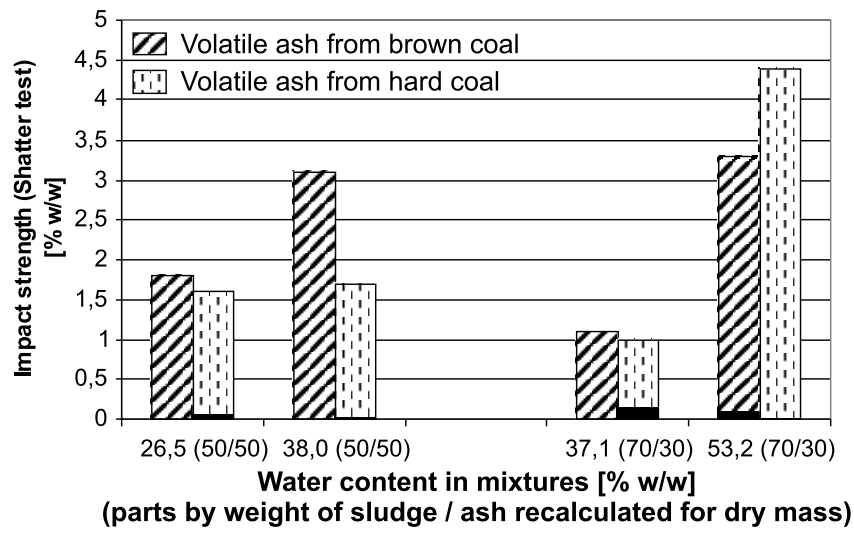

Figure 2. The impact strength of the granulates depending on the water contents in the mixture and the origin and proportion of raw materials

The test results show that the assumed method for the improvement of the mechanical properties is not adequate. Despite the fact that the strength of the samples produced from the mixtures of grater water contents is higher, the mentioned increase is small and the granulates are still subject to crushing under a slight load (compressive strength $<0,5 \mathrm{kG} / \mathrm{cm}^{2}$ ). The reason for the mechanical strength increase as long as the water content increases can be the hydration reactions of volatile ash during the hardening process.

In the three cases of the application of the ash from brown coal the mechanical strength of the granulates is higher, which can be connected with the presence of grater contents of active constituents (including free lime) responsible for the binding properties.

Further improvement of the mechanical values by increasing the water content at the assumed hitherto not complete hydration of ash binding constituents is impossible, due to technical reasons. Too high moisture content in the mixtures generates difficulties in the same granulation process.

The next step in the creation of the technology concept was taking up the trials to utilize another granulation technique. The disk granulator, which is in common use, simple in service and of low operating costs device was exchanged with the granulator with a ring-type mould being a more complicated device of greater operating costs. The dominating factor comp ressing material in those devices is the action of external forces (pressure) that leads to an increased mechanical strength of the product.
The technological tests carried out on the aforementioned granulator allowed to obtain the products of very good mechanical strength, greater than that for disc granulators, as regards both the granulates containing in its contents the volatile ash from hard coal and brown coal, pointing out to brown coal (Table 2).

Table 2. The compressive strength of sludge-ash granulates obtained according to various methods

\begin{tabular}{|c|c|c|c|c|}
\hline Granulator (method) & \multicolumn{2}{|c|}{ Disk (coating) } & \multicolumn{2}{|c|}{ Mould (pressure) } \\
\hline Mixture & \multicolumn{4}{|c|}{$\begin{array}{c}\text { sludge: ash (parts by weight of dry } \\
\text { mass) }-70: 30 \\
\text { total water contents in mixture - } \\
34,2 \div 37,1 \% \mathrm{w} / \mathrm{w}\end{array}$} \\
\hline Type of ash & $\begin{array}{c}\text { brown } \\
\text { coal }\end{array}$ & $\begin{array}{l}\text { hard } \\
\text { coal }\end{array}$ & $\begin{array}{c}\text { brown } \\
\text { coal }\end{array}$ & $\begin{array}{l}\text { hard } \\
\text { coal }\end{array}$ \\
\hline $\begin{array}{l}\text { Compressive } \\
\text { strength, } \mathrm{kG} / \mathrm{cm}^{2}\end{array}$ & $<0,5$ & $<0,5$ & 27,4 & 21,0 \\
\hline
\end{tabular}

According to the calculations presented previously the quantity of potassium in the granulates, containing volatile ash from brown coal, does not meet the requirements made for organic and mineral fertilizers (Figure 1). Despite that it was selected as a target constituent, due to greater mechanical strength of the granulates and the known fertilizing values of the ash from brown coal ${ }^{1}$. To meet the requirements made for the organic and mineral fertilizers, it was necessary to modify the contents of the mixture by supplementing it with the constituent contributing potassium in the form assimilable by plants. The standard mineral fertilizer - potassium chloride - was applied as a modifier. The calculation of an optimal quantity of the modifying agent addition was made, assuming that the quantity of potassium in the granulate must also provide for the ratio between potassium contents and phosphorus in the oxide form content equal to 2 , recommended by agrotechnicians. As a result of the calculations, the formulation of sludge-ash granulate was obtained, which will ensure receiving the product with fertilizing values, for organic and mineral fertilizers.

Based on the performed tests, whose selected aspects are presented in the work, the technological concept was elaborated for the production of the granulated product with the fertilizing values, making it feasible for the use in agriculture and land reclamation.

Communal sludge, meeting the requirements of the ordinance $^{7}$, volatile ash from brown coal and potassium fertilizer in the form of potassium chlorine in proportions 70:30:30 parts by weight of the dry mass serve as raw materials in the technology.

The technology is composed of four main unit operations: i) sludge pre-drying to the level of the water contents of $40-50 \% \mathrm{w} / \mathrm{w}$; ii) the mixture of the pre-dried sludge with other mixture constituents; iii) granulation of the mixture in the mould type granulator; iiii) drying the obtained raw granulate to the water content below $5 \% \mathrm{w} / \mathrm{w}$.

The lot of the products was manufactured according to the presented concept, which was subject to assessment in the scope of fertilizing and mechanical properties. The informative lot of the granulate was characterized by the contents of macroelemnts allowing to qualify it as the organic and mineral fertilizer: the organic matter $35,73 \%$ $\mathrm{w} / \mathrm{w}$, total nitrogen $1,70 \% \mathrm{w} / \mathrm{w}$, phosphorus $\left(\mathrm{P}_{2} \mathrm{O}_{5}\right) 3,62 \%$ $\mathrm{w} / \mathrm{w}$, potassium $\left(\mathrm{K}_{2} \mathrm{O}\right) 8,43 \% \mathrm{w} / \mathrm{w}$. Good compressive strength $\left(15,1 \mathrm{kG} / \mathrm{cm}^{2}\right)$ and the regular shape of the grains 
enable to utilize standard agricultural machinery for their application. The product is characterized by a slightly earthy odor and does not show any tendency to mould growth and spoilage under dry air conditions.

\section{SUMMARY OF RESULTS}

A course of proceedings at the elaboration of the new technology presented in this work does not contain all the problems that should necessarily be taken into account, i.e. the problem of sludge properties changing within the time and, thereby, a necessity to modify the formulation in order to obtain the product meeting the requirements of the aforementioned ordinance of the Minister of Agriculture and Village Development ${ }^{8}$. Taking into account the mentioned aspects will ensure the versatility of the technology as well as obtaining the commercial final product of the required properties.

The works on the elaboration of the technology for soil conditioning agent from sludge was realized within the frame of Ministry of Science and Informatisation 2P 06 S 00526 grant.

\section{LITERATURE CITED}

(1) Prętnicka K.: Review of agricultural utilization of byproducts of burning (in Polish), Proceedings of VIII International Conference „Ashes from Power Engineering”, Międzyzdroje, 2001, 227 - 243.

(2) Siuta J.: Land Reclamation (in Polish), Institute of Environmental Protection, Warszawa, 1998.

(3) Siuta J.: Natural using of sewage sludges (in Polish), Ekoinżynieria, 1995, 2, $10-14$.

(4) Rosik-Dulewska Cz.: The hygienization of sewage sludges by the mineral waste materials (in Polish), Proceedings of VI Polish Scientic - Technical Symposium „Enviromental Biotechnology”, Wrocław, 1999, 203 - 212.

(5) Robak J., Kubica K.: Elaboration of procedures for technological evaluation of fine-grained materials compacting processes (in Polish), Documents of IChPW 2001, unpublished report.

(6) Kubica K., Robak Z., Robak J.: Granulated auxiliary materials for metallurgy in IChPW investigations (in Polish), Archive of Foundry, 4, 13, 2004, 145 - 150.

(7) Journal of Laws of Republic of Poland No 134, point 1140, 2002.

(8) Journal of Laws of Republic of Poland No 236, point 2369, 2004.

(9) $\mathrm{PN}-75 / \mathrm{C}-04646.1$ „Water and wastewater. Special tests of sludges. Determination of contents of water, dry matter, organic and mineral substances in sludge".

(10) PN-75/C- 04576.17 „Water and wastewater. Examination of nitrogen compounds contents. Determination of total nitrogen by the Kjeldahl's method in sludge".

(11) PN-75/C-04537 „Water and wastewater. Examination of contents of phosphorus compounds. Determination of total phosphates in sewage sludge".

(12) PN-G-04528-10:1998 „Solid fuels. Determination of ash chemical composition. Determination of sodium dioxide $\left(\mathrm{Na}_{2} \mathrm{O}\right)$ and potassium dioxide $\left(\mathrm{K}_{2} \mathrm{O}\right)$ ".

(13) Rumpf H.: Grundlagen und Methoden des Granulierens, Chemie Ingenieur Technik, 1998, 70, 6, 599 624.

(14) Pietsch W.: Systematische Entwicklung von Verfahren zur Kornvergrößerung durch Agglomerieren, Chemie Ingenieur Technik, 2002, 74, 11, 1517 - 1530. 